\title{
Reflections by Some Jordanian EFL Lecturers on Salmon's Five-Stage E-Learning Model and Its Possible Application to Teaching English in Jordan
}

\author{
Ahmad Alkhawaldeh ${ }^{1}$ \\ ${ }^{1}$ University of Jordan, Amman, Jordan \\ Correspondence: Ahmad Alkhawaldeh, Professor of TEFL at the University of Jordan, Amman, Jordan, E-mail: \\ alkhawaldeh2013@gmail.com
}

Received: November 10, 2019 Accepted: January 14, 2020 Online Published: February 6, 2020

doi:10.5539/ijel.v10n2p229

URL: https://doi.org/10.5539/ijel.v10n2p229

\begin{abstract}
This study attempted to evaluate Gilly Salmon's Five-stage e-learning Model and its possible contribution to learning English language skills by surveying the related literature and obtaining perspectives of some EFL lecturers in Jordan during the 1st semester, 2018-2019. A convenient sample of twenty EFL lecturers participated in a semi-structured interview to reflect on the contribution of the five-stage model to English language instruction. The study revealed some strengths and drawbacks (reservations) of the above model. While acknowledging the existence of several positive attributes of this model such as exhibiting coherence and being structural and developmental and featuring the engagement of learners via collaborative language learning, this model, according to some EFL specialists, demands further improvement to highlight, for instance, face-to-face mode of language instruction and to be more spiral and bi-directional. The study called for integrating assessment into the model to monitor learner's learning progress. It also called for achieving independent language learning and enabling learners to transfer their learning beyond the model's final stage of development. It was suggested that the above model should be modified to account more adequately for online English language learning.
\end{abstract}

Keywords: online learning model, online instruction, English language learning, CALL, e-learning

\section{Introduction}

There has been an accelerating trend in higher education both worldwide and locally in Jordan which calls for implementing online instruction. World universities are increasingly interested in the shift from traditional to nontraditional modes of learning (Betts, 2017). Friedman (2018) asserted that this growing field will witness a rise in enrollment into online learning and so university courses will experience the use of new technologies to have further contribution to specific fields and to teaching certain profession-related skills. Hence, the above sector strives to integrate ICT in its strategic plans, courses as well as teaching strategies (Alkhawaldeh, 2017; Conole, de Laat, Dillon and Darby, 2006).

Higher education experiences an expansion in online education as it attempts to fulfill the demand to meet accountability requirements (Ni, 2018). Crowley and Ryan (2017) highlighted the role of ICT in higher education. Meanwhile, some research undertaken by Menchaca and Alkhawaldeh (2014) indicated several barriers that may impede the adoption of information and communication technology in the instructional process such as the lack of knowledge and confidence in the new educational technology in addition to attitudes towards it and the resistance to change.

The field of language e-learning whether web-facilitated or in the shape of a hybrid mode or fully virtual has enjoyed a similar attraction by language specialist (Blake, 2011). Hence, a major interest is now underway in online language learning (OLL). Specialists are now looking for implementing a model that can achieve the learning outcomes of the increasing numbers of higher education students. This, certainly, matches with the trend to assure quality of higher education administered via online instruction (Oliver, 2011). Undergraduate and graduate programs in language teaching and applied linguistics have included CALL modules within their study plans to account for the needs and demands of the higher education community.

Still, there is a continuing debate, among researchers and academics, over what model to adopt to maximize benefit from online instruction. The present study, primarily, attempts to present Gilly Salmon's five-stage model 
by evaluating it from the perspective of English language specialists and the related literature.

When firstly introduced, Salmon's five-stage model (also recently referred to as a framework by Salmon herself) of online instruction received wide attention and so was applied by several institutions. According to Moule (2007), this model received uncritical citations when it was first applied. Meanwhile, it received criticism by few scholars interested in online education though several others praised it. Locally, in Jordan, this model has not, to the researcher's best knowledge, been evaluated and, therefore, this topic seems worthy of investigation. Salmon (2016) acknowledged that research is currently not providing answers to this problem and more models are essentially needed to demonstrate the transferability as well as the scalability, according to her, of e-learning.

Online learning can be fully online, with all instruction being implemented through the Internet, or via online elements being combined with face-to-face interaction in what is referred to, at the present time, as 'blended learning' (Bakia, Shear, Toyama, \& Lasseter, 2012) citing Horn and Staker (2010). Bakia et al. (2012) reported on different types of course redesign models such as (1) supplemental model which provides supplementary technology based learning to traditional lecturing, (2) the replacement model which decreases in-class learning and replaces it by online interactive learning, (3) the 'imperium model' which replaces traditional learning with learning based on computer software to become personalized, (4) fully online model which eliminates lecturing and replaces this by online learning and (5) the linked workshop model which can be used as a remedial and developmental instruction.

The ICT educational applications are embraced by recent theories of learning such as the constructivist theory which has a premise that knowledge is perceived as dynamic and that the learning process experiences the ever-lasting change situation. Vygotsky (1978) argued that social interaction plays a significant role in the development of the cognitive function and high order thinking. Therefore, the design of ICT learning, teaching and training needs to be based on the constructivist theory where knowledge construction goes through active participation of students using collaborative methods of learning undertaken via a negotiable learning context (Gray, Ryan, \& Coulan, 2003). Berger (2013) and Abdullah and Hassin (2013) called for a theory for online learning and teaching.

According to Yusuf (2011), the use of ICT will not achieve its effectiveness unless teachers display competency and, at the same time, hold a positive attitude towards information and communication technology. A similar attitude was also shared by Jaffer, Ngami and Czerniewicz (2011) who pointed out that the use of ICT has to be prioritized in order to attain effective language instruction. According to Light (2009), if ICT is integrated into a top quality learning environment, it can strengthen knowledge as well as enhance the learner's thinking strategies. Likewise, Rogers (2000) emphasized that attitudes towards technology represent a significant aspect to achieve effective technology application. Similarly, Davis (1989) reflected on the positive attitudinal precondition towards technology to ensure effective use of it. The same was also affirmed by Sun, Tsai, Finger and Chen (2008) and Piccoli and Ahmad (2001) who also highlighted efficiency and satisfaction in using technology.

Among the related models is the Maye's conceptualization cycle which looks at e-learning as a process of conceptualization, construction and dialogue (Manchester University Blackboard training resources, 2019). Another model was proposed by Laurrillard's called the 'conversational model' which underscores dialogue between learner and teacher. Moule (2007) introduced the e-learning ladder. Finally, community of practice as a concept was first introduced by Lave and Wenger in the year (1991). Related learning, according to this model, is supposed to grow naturally due to the shared interest among the community members in a particular field. It can be developed to acquire knowledge in a certain area. According to Wenger (2015), there are three important elements of this approach which include domain, practice and community. In the educational realm, this can be used to ground school learning by sharing in communities of practice about school subjects. It can also be extended to incorporate out of school learning. Finally, it can be used by extending learning beyond school learning as a life-long experience (Wenger, 2015).

\subsection{Description of the Five-Stage Model}

Salmon (2003) developed a model widely referred to as the five-stage model. Each stage of the model takes into consideration several computer-related skills and learning skills required to achieve, according to her, developmentally structural mode of learning. An illustration of the model is provided by Figure 1 below. 


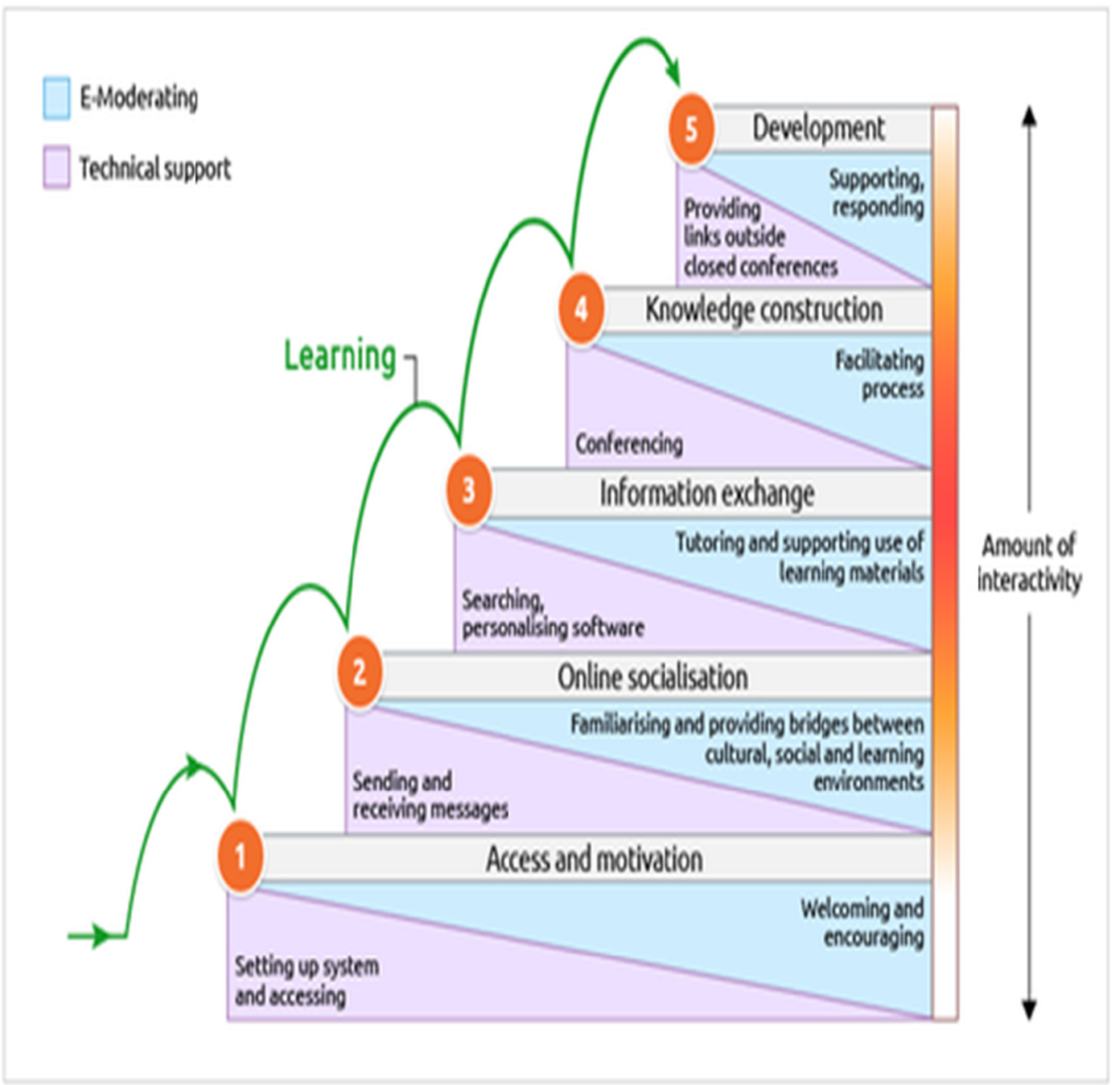

Figure 1. Gilly Salmon's five-stage model

Source. https://www.gillysalmon.com/five-stage-model.html

Salmon (2003, as cited by Moule, 2007 p. 38) described the five-stages. First stage encompasses (Access and motivation) which embodies setting up process and accessing learning by means of welcoming and encouraging. The second represents (Online socialization) which embodies the process of sending and receiving messages. This stage requires familiarizing and providing connections between various cultures, social and the different learning environments. The third stage embodies (Information exchange) as a process which is implemented through searching and personalizing software and also through facilitation of tasks as well as supporting use of the related learning materials. The fourth stage represents (Knowledge construction) which is predicted to be achieved via conferencing and facilitating process. The final stage encompasses (Development) which provides links outside closed conferences by means of the processes of supporting and responding. Gilly Salmon described the model as a structural developmental one which is, according to her, based on scaffolding learning. The last stage, according to her, is the culmination of the learning process performed by the learner where he or she is expected to get a representation of reflection, thinking critically and realizing self-evaluation. Some scholars such as Watts (2010), as will be discussed below, associated this model with the 'communities of practice approach'.

\subsection{E-Learning Evaluation Framework}

Khan (2004) provided eight dimensions to evaluate online models which are:

First, pedagogical: Which has to do with both learning and teaching and it concerns issues of content, goal, audience and media analysis, organization, design approach, strategies and methods of the e-learning contexts. 
Second, technological: Which is intended to assess technology infrastructure in e-learning contexts by encompassing infrastructure planning, software and hardware.

Third, interface Design: This concerns the general look and sense of e-learning programs which embodies issues that are related to e-learning site design, e-learning content design, usability examining and navigation.

Fourth, evaluation: This handles assessing learners, evaluating instruction as well as learning context.

Fifth, management: This concerns up-keeping of the learning environment and information distribution.

Sixth, resource support: Which assesses online support and resources used to create meaningful learning contexts.

Seventh, ethical: Which examines the social and political impact, bias, cultural diversity, geographical diversity, information accessibility, learner diversity, protocol as well as the legal concerns.

Eighth, institutional: Which handles administrative affairs, student services as well as academic affairs that have to do with e-learning.

Oliver (2011) mentioned above, did not see much difference between assessing the quality of instruction whether it is face to face or online. He adopted a set of benchmarks for quality assessment of instruction in higher education.

\subsection{Previous Studies}

Through surveying the world literature, evaluative and critical studies on online models appear to be sparse. The following are related studies that sail with the five-stage model and those that sail against it.

First, some researchers praised the five-stage model for its clarity and so it was applied through structuring online projects and programs (Lisewski \& Joyce, 2003; Hughes, Ventura and Dando, 2004). On the other hand, Moule (2007) praised the five-stage model to e-moderating as a coherent model upon which to base the design of online learning in higher education. Then Moule argued that in spite of its increasing popularity, there are issues that such a model is becoming an established discourse, which is used as an outline for online teaching and learning. The five-stage model may not be the solution, according to Moule, as it appears and therefore, alternative models of e-learning have to be considered. Likewise, Chowcat (2005) found out that the five-stage model is ineffective, especially when used for the purpose of the training of UK mentoring head teachers. Chowcat proposed that the model assumes the existence of an exclusive online situation which should be used to back up a course administered over one week for every single learning stage. Chowcat reached the conclusion that the five-stage model may not freely apply to various learning circumstances.

Watts (2010) examined the application of three pedagogical models to designing and delivering blended workshops related to online learning. The models encompassed the five-stage model for both online teaching and learning, the learning ladder and finally communities of practice. The workshop, they conducted, aimed at introducing participants to several pedagogies and technologies which are used in blended learning. Some of the participants were interested in online learning while other participants wanted to learn how to improve the online components of their current courses. The five-stage model for e-moderating was used by the tutor. The target model was presented to the partakers as they progressed through the model stages. Participants did not feel at ease with issues such as socialization, the role of the moderator, technology, face-to-face sessions, speed of progress through the different stages and finally application to teaching practice. The participants in the workshop compared the five-stage model to the model of e-learning ladder and finally compared it with communities of practice model to see how much they address such issues.

Lisewski and Joyce (2003), in their examination of several frameworks including the five-stage model, stressed the need for e-learning technology to establish a special identity and so having a knowledge background which they saw as strengths of this model. At the same time, they warned that these frameworks have the 'dangers in them becoming too reified within an increasingly commodified higher education...environment' (p. 55). They encouraged conducting a critical debate over related issues, according to them, which encompass 'professional reflexivity and contestation' (p. 55) in the realm of learning technology.

Zhang and Wang (2017) applied a CALL model to teaching the skill of reading. They first analyzed the advantages and disadvantages of the model. Then they analyzed the teaching situation and after that they integrated the CALL model with various aspects of the reading skill. They finally analyzed the teaching results via using the CALL model. They concluded that the effectiveness of the CALL model was proved in both theory and practice.

Most of the research that has supported Salmon's e-learning model focused on direct calls to use the model. For example, Good (2001) published an article that indicated a trend towards online pedagogy teaching and learning and summed up this direction by calling for pedagogies that align with new technologies. Barker (2002) supported the above innovation by highlighting the role of the online tutor. The new trend towards structuring online 
programs has received a wide popularity according to Lisewski and Joyce (2003) therefore, calls have been on the rise to examine Salmon's five-stage e-moderating model in the realm of the learning technology profession.

Stephenson (2001) and Barker (2002) praised the online tutor innovations in education and teaching. Likewise, Bennett and Marsh (2002) suggested the gradual development of the experience of online tutors taking into consideration the developments in the field of teaching and education. Also, Thorpe (2002) reflected on reconsidering learner support and mentioned the challenge of collaborative online learning. Likewise, Lisewski and Joyce (2003) reflected on the wide demand of the five-stage model which is, according to them, is transparent and so it was applied to the design of online programs.

Salmon (2003), herself, pointed out that the e-moderating model was constructed on the basis of experiences to facilitate online networking and collaborative work. Its major principle, according to her, seeks to provide a model for e-moderators in order to support student engagement and learning via online by relying on the constructivist theory and its related pedagogy.

Due to what is perceived by other researchers as drawbacks of the five-stage model, some researchers criticized the model and had reservations on it and they announced their justifications. According to Moule (2007), the five-stage model is limited because of the negligence of the wide range of e-learning approaches that are possible to be used within the field of computer-mediated communication and, hence, the ignorance of the various learning theories. Likewise, Chowcat (2005) found the model ineffective to train the head teachers in the UK. The model assumes the use of an exclusive online environment to support a course which followed a specific time plan which extended over one week to cover each of the above five-stages. The course structure, according to Chowcat, proved to be difficult to achieve effectiveness in the school year because it does not easily transfer to various learning conditions.

Jones and Peachey (2005) raised questions regarding the socialization stage suggested by Salmon's model and so they included in their instruction a face to face interaction mode. On the other hand, Berge (2013) said that Salmon looks at the online classroom from the teacher's perspective which she referred to as the 'e-moderator' The e-moderator's role is to support human communication using processes such as (1) modeling, (2) conveying and (3) knowledge and skills building. She reflected on this model by saying that it follows a constructivist not an instructivist way.

A teaching and learning model was suggested by Schmidt and Brown (2004) which represented both traditional and online instruction. The learning and teaching process was described as continuous which embodies examining teaching style, assessing the learning styles, studying and selecting online methods for learning and teaching and finally experiencing implementation, reflection and revision. Further, following a five-stage model and in the absence of a learning community, learners are considered passive receivers of knowledge, according to Armitage and O'Leary (2003).

Chang and Windeatt (2016) mentioned that there is evidence which supports collaborative language learning whether this is managed through face-to-face or via online teaching. They followed 47 university students who participated in an online English course which lased fifteen weeks. They gathered data from reflective journals, written assignments, questionnaires and the comments posted by the participants and also the e-mails between participants and their instructors. They identified three themes which encompassed peer reading work, provision of feedback, and group work. The main themes included the value of social collaboration, time to assist collaboration to grow, and the impact of the gradual development of student's confidence. Collaboration patters were influenced by the sense of collaboration and learner's mutual trust.

Alhamami (2017) conducted a study which used mixed methods to investigate the intentions of language learners to learn a foreign language through face-to-face mode of learning and through online learning using a theory developed by Ajzen's referred to as planned behavior. He collected data by using questionnaires, interviews and treatments with two groups: the face-to-face group which included 690 participants and another group that learned through online language learning whose number was 296. The study showed that the intentions of language learners were influenced by their attitudes, their beliefs and their views about their ability. These factors were considered in predicting learner's ability to perform in online language learning. The study also revealed preferring language learning via face to face learning.

Sydorenko, Daurio and Thorne (2017) addressed the opportunities of practicing second language interaction through simulations for learning of pragmatic communication. They used a sample of $12 \mathrm{EFL}$ proficient learners who completed 6 simulated conversations which focused on making a request in formal contexts. Collected evidence of learning was assessed in a micro-genetic way by the comparison of data across the target simulated conversations. This was also matched by means of surveys, written reflections as well as interviews. Results of 
the study showed that the participant gained both content as well as linguistic forms from speaking models and also from their interactions in simulations. The participants highlighted the positive gain from the program, its predictive accuracy and authenticity.

Shulze (2017) asserted that, currently, a growing push is underway toward teaching more language modules online and this, according to him, is on the rise due to their social and interactive nature. They are supposed, according to him, to broaden students' access to quality education and also due to the affordance of independent learning. He searched into the nature of the transition between online language learning and normal classroom learning. He found out that the statistical data led to identifying learners' paths over ten-year period while qualitative data provided in-depth information about independent learning paths as well as learners' curricular decisions.

Sharifi, AbuSaeedi, Jafaygohar and Zandi (2018) emphasized that the effectiveness of computer-assisted language learning has been a debatable topic. They provided a meta-analysis regarding the language learning impact of computer-assisted English language learning on a wide range of study attributes. One hundred forty studies (140) were analyzed to compare between effect of CALL and traditional face-to-face learning. Among other results, the study revealed that computer-assisted language instruction had a total medium impact on English language improvement.

$\mathrm{Li}$ (2018) reviewed twenty-one articles on computer-mediated collaborative writing which were published from the year 2008 to the year 2017 in well-known journals. He performed an analysis of such articles including context and technology, writing task, theoretical/practical framework, focus of research, and data and methods. Three main themes were identified which encompassed interaction/writing process, product/outcome, and students' perceptions and specific research types. The researcher also discussed the pedagogical implications of this research in terms of writing tasks, grouping, assessment, student training in addition to future research directions embodying broader learning contexts, methodological innovation, collaborative writing tasks and several research components which require further investigation.

\subsection{Research Questions}

Taking into consideration the rare critical studies that tackled Gilly Salmon's model and its potential impact on language learning, the present study attempted to evaluate the potential impact of this model of online learning on English language learning skills from the perspective of EFL specialists and through some literature review. The following are the research questions.

1) What are the strengths of the Salmon's five-stage e-learning model?

2) What are the weaknesses (reservations) of the Salmon's five-stage e-learning model?

3) What are the concerns about the five-stage model as perceived by university EFL lecturers?

4) What is the proposed framework of online English language learning that can be devised on the basis of the results of this study?

\section{Research Design and Methods}

The present study adopted a qualitative interpretative approach. Review of the related literature relied on the most related studies by deriving the critical evaluative studies and analyzing them with special focus on the above model. As for the interviews with the target university EFL lecturers, these lecturers were selected on the basis of their specialization and interest in the field of e-learning and its relevant applications.

\subsection{Participants}

Twenty EFL lecturers of all ranks with various teaching experiences and whose specialist areas represented different related language teaching and applied linguistics sub-disciplines participated as interviewees in the present study during the 1st semester of the academic year 2018-2019. They were selected through a convenient sample to achieve the purpose of this study.

\subsection{Interview Instrument}

The researcher used the interview instrument which was based on the related literature to collect related data. The interview schedule included items that elicited responses from the interviewees regarding the strengths and weaknesses of the above model. Related literature was surveyed to find out more about the strengths and weaknesses of the above model.

\subsection{Validity}

To establish the validity of the instrument, a content validity was ensured by forwarding the instrument to seven 
professors who are known for their interest and keenness in the field of online instruction and computer assisted and mediated language learning. All considered the instrument appropriate for the purpose of evaluating the five-stage model and few of them suggested the modification of few items which were modified upon their recommendations. The interview questions were reviewed.

\subsection{Reliability}

As for the interview instrument reliability, the researcher used to ask the same question to the interviewee more than once to make sure that the obtained answer is likely to recur if the same question is asked more than once. Also, three interview transcripts were sent back to three interviewees who fully confirmed their responses which they gave in the first interview with them. They fully confirmed the responses they provided in the first model comparison.

\subsection{Challenges Encountered During the Implementation of the Study}

1) Not all professors were keen to participate in the study for several reasons which the researcher did not explore.

2) The researcher noticed a variation in experiences in online language learning.

3) The world literature, in the field of this study, seems to be scarce.

4- Participants' responses may be restricted to degree of familiarity with the model and its applications.

\subsection{Data and Sources of Data}

The data of the present study were collected in two stages: First the related literature was surveyed to examine the strengths and weaknesses as reported by various researchers in the field of online instruction. Secondly, interviews were conducted with a number of concerned university instructors to collect data about Gilly Salmon's model of online instruction to measure how much it is effective in the field of English language learning.

\subsection{Data Collection Techniques}

This study was implemented during the year 2018 where the researcher first contacted via email the respondents to obtain their consent to participate in this study. As for the interviews, they were conducted personally in a face-toface mode of communication. They were recorded to make it easy to be accessible when needed. Each interview lasted around 20 minutes to answer a set of questions which concerned the evaluation of the five-stage model and its impact on the acquisition of the English language skills, the strengths of the five-stage model, the weaknesses of the five-stage model, the theories of learning which this model rests on, the extent to which this model can be applied to English language learning and, finally, the participant's suggestions concerning the adoption or modification of this model.

\subsection{Implementation of Interviews}

The interview lasted twenty minutes which was conducted with twenty EFL lecturers specializing in teaching English and CALL who reflected on the importance of the five-stage model and its potential impact on the acquisition of English language skills, its strengths and weaknesses and provided their suggestions concerning this model. Interviewees were contacted to hold an interview with them individually and they were asked a set of questions as outlined above. Interviews were recorded to facilitate subsequent data analysis. Immediately after the interview, the researcher started to write down and summarize the content of the interview on a separate paper coded to facilitate comparing and cross matching with other findings.

\subsection{Qualitative Data Analysis}

As mentioned above, an interpretative approach was followed in the explanation and understanding of the collected data. A content analysis approach was adopted to analyze the data gathered from interviews with the twenty EFL lecturers. Three main steps were followed which began with (1) development as well as use of codes, (2) the identification of significant themes, patterns as well as relationships, and (3) Summarizing the collected data.

As for the interviews, recorded data were transferred into written verbatim to begin the data analysis process. Responses on each of the interview questions were grouped and coded in order to search for patterns and themes in these responses to answer the above research questions. Strengths and weaknesses of the above model and its potential contribution to the acquisition of English language skills as expressed by the study's participants were identified. Both the phrase and sentence were adopted as analysis units. 


\section{Findings}

\subsection{Strengths of the Five-Stage E-Learning Model}

First, the five-stage model was evaluated by the world literature as follows:

Table 1. Strengths of the five-stage model as revealed by the related literature

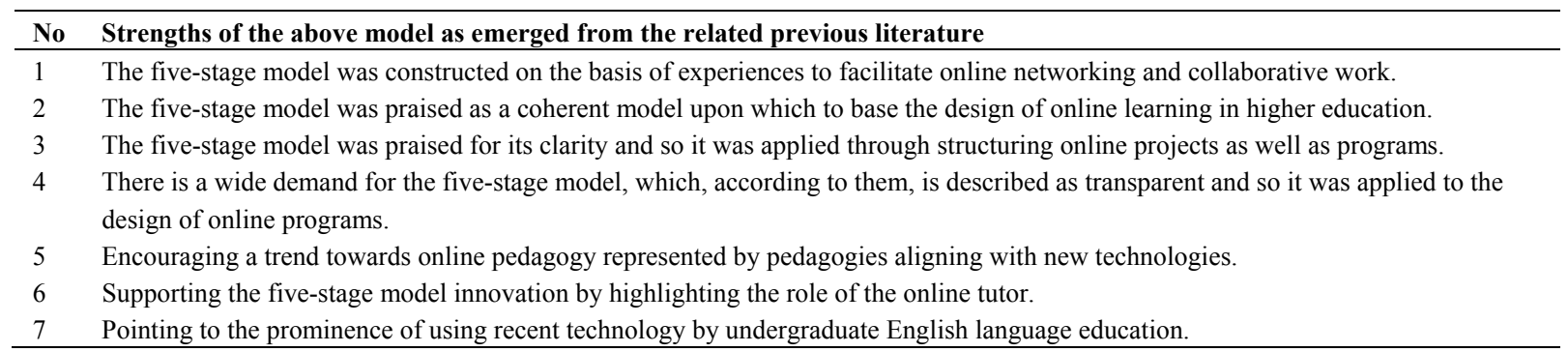

Table 2. The strengths of the five-stage model which emerged from interviews with concerned university EFL lecturers

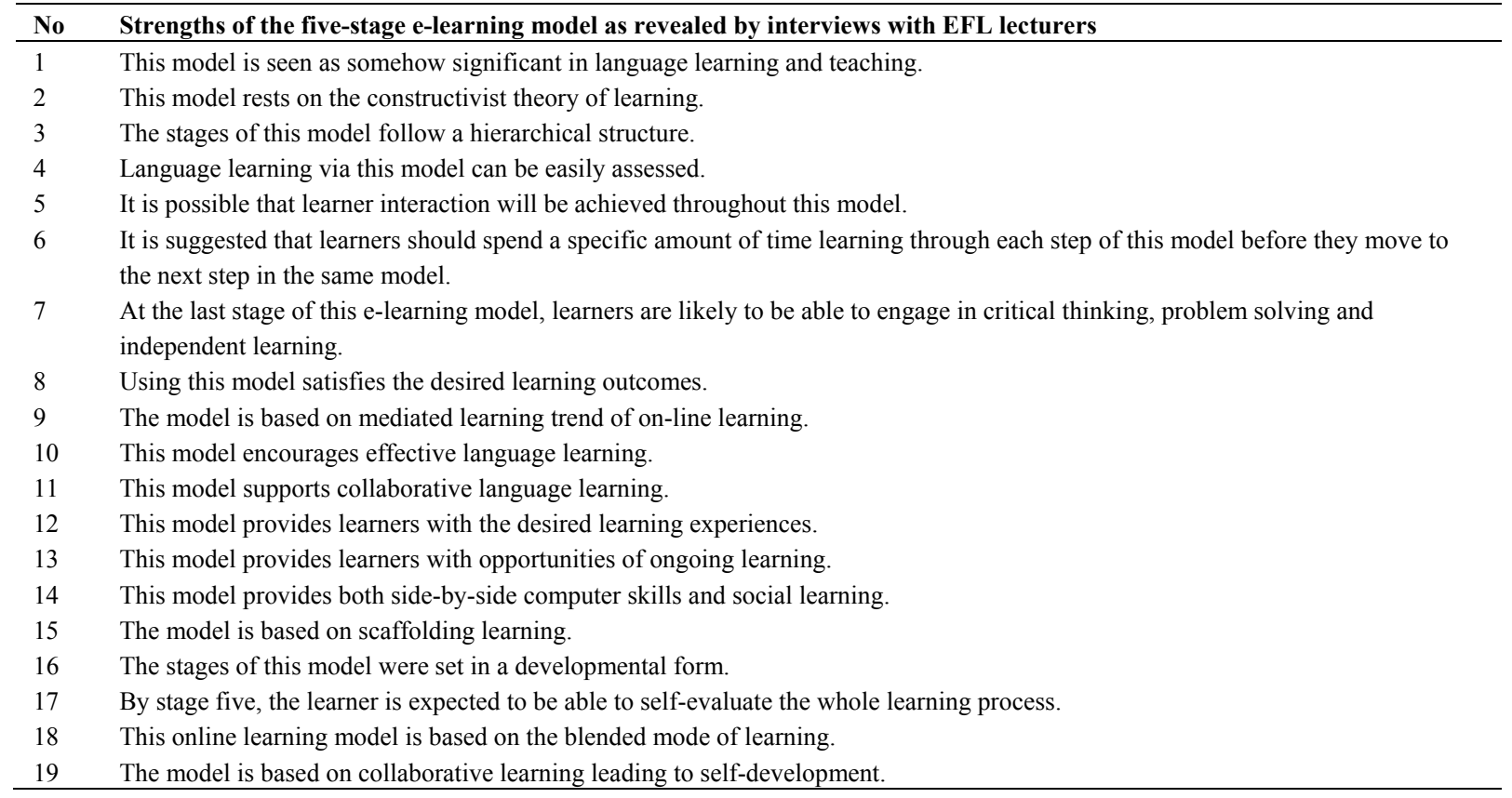

\subsection{Weaknesses (reservations) of the Five-Stage E-Learning Model}

Table 3. The weaknesses (reservations) of the five-stage model as revealed by the related literature

1) The inattention by the five-stage model to the broad collection of e-learning approaches that may be used within the field of computer-mediated communication

2) The lack of effectiveness of the five-stage model to use e-learning as an element of a unified approach which can include face-to-face style of instruction.

3) This model may not easily transfer to several learning situation.

4) Following a five-stage model and in the absence of a learning community, learner may not experience active reception of knowledge.

5) Teaching a disconnected form of information technology course within the scope of a constructivist learning milieu was also at stake in the five-stage model.

6) The model's negligence, according to a limited number of researchers, of the learning theories

7) Preparation of e-moderators to accommodate all learner's learning styles, motivation and strategies is also at stake in this model.

8) The socialization process as characterized by stage two of the model was also questioned on the ground that if socialization is achieved via stage-one there is no need for stage-two socialization. 
Responses to the interviews concerning EFL university lecturers' critical evaluation of the five-stage model and its possible impact on the acquisition of English language learning skills.

Table 4. A summary of the weaknesses (reservations) of the five-stage model as emerged from the interviews with twenty university lecturers

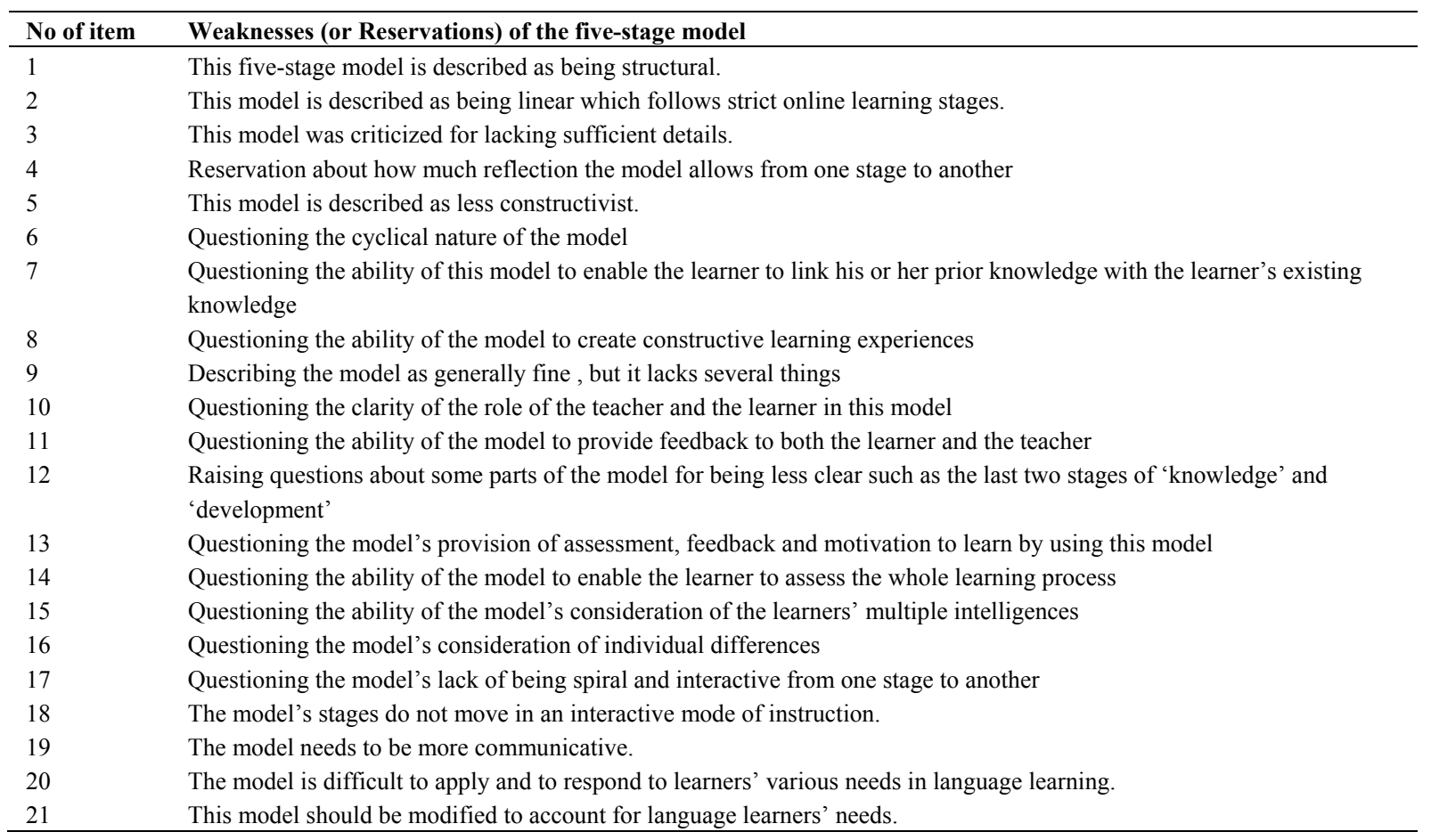

Based on the study's interviews, there seems to be a tendency to adopt the five-stage model though several modifications were suggested by interviewees. Various issues of the five-stage model were reflected on by the interviewees in this study which encompassed the structural and linear nature of the model, its ability to enable the learner to match prior knowledge with existing knowledge, lack of clarity of the role of both teacher and learner, lack of sufficient feedback being provided by the model and insufficient consideration of individual differences and learning styles.

Interviews also revealed positive attributes of the model such as being straightforward, staged in five steps and based on mediated mode of online learning. The following are examples of the responses provided by the interviewees on the five-stage model.

A professor of applied linguistics affirmed that the model is structural and looks linear than being fully constructivist. The idea that a learner may pass through stages one after another may not encourage him or her to reflect enough, a thing which may not line up with reflection theories widely in public learning and teaching. Another professor of applied linguistics was interviewed who questioned the lack of the cyclic nature of the five-stage model and then questioned the existence of reflection in it. He also reflected on the linear nature of the model that begins and ends by the fifth stage. He said:

This [five-stage] model or approach of online instruction just puts the English language learner in a learning situation where he or she will not be able to match, for example, existing knowledge with prior knowledge. I think this does not go with the constructivist theory. This model assumes that a constructivist learning process will take place, but, in reality, this cannot be ensured unless the model is experimented with. (Interviewee 1)

Another professor of applied linguistics was interviewed who taught graduate courses and CALL courses and supervised graduate students. He said that the model is generally fine, but it lacks several major things. He questioned the lack of feedback in the model and also, like the preceding professor, questioned the issue of the cyclic learning mode which the model should exhibit. He also questioned the lack of clear skills expected of the teacher and the students. The last two stages were not fully clear to him which embodied knowledge construction and development phase in the model. 
It is questionable if this model can be applied to all specialty areas and also can be applied to all levels of the students. The issue is that it does not return to previous steps. What about assessment, motivation and feedback and how to reinforce students and how to assess the whole process. (Interviewee 2)

The same interviewee also reflected on the absence of teaching methods to be used and the learning principles that govern the whole learning process.

An assistant professor had reservations on the applicability of the model and he ascertained that the model is set to address online instruction and, in general, it addresses it without sufficient details about the major components that a potential model of online instruction should have. He regarded the following as requirements of a good model of online learning and teaching which encompassed, according to him, stages such as a welcoming phase, social interaction, knowledge construction and finally the development of the learner via the interaction with the learning stuff, but still individual differences are under-valued, according to him.

An applied linguistics professor said that the model is supported by a theory that packs it up. He saw the interaction characteristic of the five-stage model as a strength of this model. He valued the existence of the five-stages in the model considering this a clear and straightforward attribute of this model. He highlighted the wide base of the model and the narrowing down attribute of this model as it hierarchically goes up. He questioned why the model was not circular or spiral. There was not enough interaction, according to him, between one stage and other stages that the learner is likely to experience.

A TEFL professor was interviewed for a round 20 minutes to reflect on the five-stage model. This model, according to him, reflects a socialization process. In his opinion, the model is hierarchical. It manifests technical and instructional facets of this model. The model goes through technical and instructional lines. Each step combines technical and social learning. He said that the model leads to final development on the part of the learner. He added:

This model is supported by the social constructivist theory. The steps do not move in a spiral or interactive mode of instruction. This model is a direct model with little interaction and circularity process. It is not clear whether this model reflects synchronization or asynchronization. How technical steps match social skills in the model remains a questionable and puzzling point. This model fits online instruction and should be more communicative. (Interviewee 7)

An applied linguistics professor was impressed by the model. He said that the model being hierarchical which embodies steps or stages is considered something remarkable. He remarked that the model is short of an assessment portion and so should have an assessment segment through the various stages. Also, according to him, the model does not illustrate how the final process, which is the development stage, will lead to further learning. The teacher's role and that of the learner should, according to him, be made clear.

A professor who teaches CALL courses to graduate TEFL students, criticized the model for being weak and does not satisfy instruction, especially as the case of the present study where English language instruction is concerned. He questioned several issues that have to do with this model such as its reflection ability, lack of clear assessment mechanism, being linear, its ability to address language learners' needs in a virtual environment and he, therefore, gave this five-stage model a low evaluation. He noticed that the model is excessively theoretical and difficult to apply. He, meanwhile, valued its step-by-step nature, being hierarchical and being based on mediated learning mode of instruction.

He said:

It may be used as a complimentary or additional tool for English learning and teaching. No control over the community of learners. Blended learning may be more suitable for this kind of subject. It needs modification to be used in language learning. It therefore needs arrangements with many people. (Interviewee 3)

An assistant professor reflected on the five-stage model.

The model seems beneficial to a certain extent in helping learners of English to strengthen their performance in it. The model seems interrelated and could be thoroughly implemented if the required sources and aids are provided. It should set the outcomes and the targeted population, the types of e-learning sites or applications. It seems constructivism and connectivism which support the model. It could be applied and used in EFL contexts. (Interviewee 17)

Results that emerged from the interviews clearly indicated that the five-stage model has certain strengths and weaknesses. Among the strengths were issues that have to do with the model being designed as a step-by-step model, being developmental or progressive and, being to a certain degree, based on mediated learning mode of 
instruction. As for the weaknesses, according to the interviewees, these encompassed the difficulty to apply this model to multiple learning situations, questioning how much the stages are progressing in an interactive way, lack of clarity in some stages of this model, being linear following strict staging mode and the lack of feedback and reflection and being less bidirectional. Also, teacher's and learner's roles are not clear in this model and finally questioning the ability of the model to enable the learner to link existing knowledge with prior knowledge of learning.

\subsection{A Possible Adaptation of Salmon's Model for Second Language Learning}

The world literature advocates re-visioning online learning models and because the five-stage model has its own positive features and shortcomings, the general trend is to attempt to improve it and include some aspects to make it more accountable for online language learning. In line with the call of the present study to get the five-stage model to be more interactive and bidirectional and to clarify what the learner and the e-moderator should do as well as clarifying what the learner should do after the final stage. Among those who were impressed by the Salmon's model of online learning were Abdullah et al. (2013, p. 226) who suggested that the model could be adapted to account for second language learning. By doing so, they predicted that the zone of proximal development will be overcome and also scaffolding learning will be achieved.

Table 5. Concerns about the five-stage model arising from the present study

\begin{tabular}{ll}
\hline No & Concerns regarding the five-stage model \\
\hline 1 & The need to get the five-stage model to be a blended learning model \\
2 & The need to get the five-stage model to be a cyclical model \\
3 & The issue of longevity of involvement in learning so as to develop a community of practice \\
4 & The issue of what to do with learning after the final stage of development \\
5 & The need for the integration of assessment of learning into the five-stage model \\
6 & The demand for the consideration of learner's strategies and learning styles \\
7 & Transferring learning via the five-stage model to normal life situations \\
8 & The need for clarifying the role of the e-moderator \\
9 & The issue of how the e-learner progresses through the stages and so becomes independent \\
10 & The lack of access to the program of learning by using the five-stage model \\
11 & The issue of handling the different learning abilities by using the five-stage model \\
12 & The role of the e-moderator in the provision of scaffolded learning by using the above model \\
\hline
\end{tabular}

\section{Discussion and Conclusion}

The current study attempted to appraise the five-stage model and its potential contribution to second language learning. The results revealed that there were lecturers who see the model should exhibit significant changes while, on the other hand, others who accepted the model and were impressed by its potential outcomes.

The extent to which the model could be applied to all students was questioned by at least one of the interviewees in this study. By referring to the related literature, Moule (2007) criticized the issue of the model being like 'a hat size that fits all' asserting that this might minimize its wide applicability. Worth pointing is that individual differences, the learning strategies and styles do not seem to be adequately visible in the model which may limit its possible effectiveness in areas such as language learning as the main context of the present study.

While the five-stage model was seen by some as a new pedagogy, it was challenged on several grounds where some criticism was directed to the structure of the model for being difficult and that, for example, stage two might not be needed if socialization is achievable in stage one. Other criticism was leveled at the model's possible lack of adequate reflection and cyclicality, according to some lecturers interviewed in the current study. The model was also criticized for the insufficient clarity of being a blended learning one. A growing trend in e-learning models, worldwide, is concerned with blended learning and experience in online learning.

Some criticism was levelled at the stages of the process of socialization in the above model. Jones and Peachey suggested the inclusion of face-to-face contact as part of this initial stage. They were not able to determine whether an 'appropriate' degree of socialization was achievable or not. Also, the structured stages mode in collaborative learning context was seen as a shortcoming of the above model. Laurillard (2002) argues that both structure and staged learning in a collaborative learning context decreases flexibility and may cause stress due to the collaborative learning process. Likewise, Chowcat (2005), found the model ineffective when used to train the mentoring head teachers in the UK. Chowcat, therefore, suggested the model should assume a special online context to be used to encourage a course run to a specified time plan over a certain week for each one of the above 
stages. The structure of the course, according to Chowcat, was considered difficult and may not be easily applicable to various learning situations.

The interviews presented several issues related to the five-stage model. The first issue is the extent of the match between the use of computer skills and social learning as proposed by the five-stage model. One of the interviewees felt that this might be difficult in the lecture room while another noticed that the application of this model needs several resources and media to be applied to language learning. The second significant issue is related to the extent to which the model is highly reflective and how much this reflection is explicit. A third issue is the extent to which the model is consolidated by learning theories, especially the social constructivist theory. In this respect, the question of how much scaffolding the e-moderator should offer to the learner to sustain learning. A fourth issue addresses the cognitive appropriateness of the social learning provided by the model. A major concern of the five-stage model is the extent to which it can be tested in reality. Berger (2013) and Abdullah et al. (2013) pointed to the lack of a theory, according to them, upon which to base e-learning of English language learning and teaching. Berger indicated that online learning principles have not seen the appropriate changes. Salmon (2016) proposed a strategic framework and, meanwhile, criticized the linear fashion of e-learning and so she acknowledged that linear modes of e-learning are not so much satisfactory. Worth pointing out that Salmon herself warns that the model should be used as a framework to be applied depending on the nature of the learning field and context. She (2016) suggested what she called a strategic framework to develop e-learning as well as pedagogical innovation to serve institutions that offer higher education. This, however, illustrates how much a model for e-learning in higher education is demandable. This was also confirmed by several scholars in online learning arena.

In conclusion, major themes which emerged from the findings of this study embodied the hierarchical stages of this model. Among the issues that were questionable was the necessity of the model to be a sort of a blended one which should combine instructivist and constructivist online modes of learning. The model was also questioned concerning the ability to incorporate the multiple learning abilities of the students and how the e-moderator can accommodate them. Also, the assessment issue in the model was also questioned. Another issue concerns the inaccessibility to access online learning using this model and finally how the model can be spiral or bidirectional.

On the basis of the previous literature and the results of the present study, the researcher suggests that the e-learning model should integrate more aspects of instructivist and constructivist modes of language learning to account for the multiple needs of online learners. A clarification of how different ability learners are going to be taught via online learning program is also needed. Developing online learning programs and courses according to university's general and specific plans and strategies. Also, there is a demand to determine and make clear the purpose of e-learning programs and how they will be undergoing sustainable development. The importance of developing existing regulations at higher education in Jordan to develop programs so that e-learning can be facilitated and integrated. The proposed framework should take into consideration the development of the learner's reflective ability. An online learning model should also consider the cyclicality of the process of language learning and teaching, therefore connections should be made between each stage and the other stages in the modified model. The online learning model should be collaborative as learners climb up to reach the last self-learning and self-evaluation level and beyond to transfer learning output and effect to similar life situations. The model should illustrate assessment of the learner's language learning. Further, the model should consider the individualization of instruction. Online language learning framework should make account of ongoing learning beyond online instruction to sustain life-long learning. Any online model, likely to be used in language instruction, should be embraced by recent innovations in language learning theories. The five-stage model could be adapted to fit the Jordanian EFL context after being modified and experimented with.

\section{Acknowledgement}

This article is based on part of the results of a sabbatical leave research supported by the University of Jordan. Therefore, the author acknowledges the support of the University of Jordan. Also the author acknowledges the participation of the university lecturers who agreed to participate in this study.

\section{References}

Abdullah, M., Hussin, Z., \& Asra, Z. (2013). M-learning scaffolding model for undergraduate English language learning: Bridging formal and informal learning TOJET. The Turkish Online Journal of Educational Technology, 12(2), 216-234.

Alhamami, M. (2017). Beliefs about and intention to learn a foreign language in face-to-face and online settings. Computer-Assisted Language Learning, 31(1/2), 90-113. https://doi.org/10.1080/09588221.2017.1387154 
Alkhawaldeh, A. (2017). The University of Jordan education students' perceptions of ICT, functions, applications, challenges and future expectations in the university's instructional process. International Journal of Instructional Technology and Distance Learning, 14(8), 3-19.

Bakia, M., Shear, L., Toyama, Y., \& Lasseter, A. (2012). Understanding the implications of online learning for educational productivity. Retrieved August 24, 2018, from https://www.sri.com/work/publications/understanding-implications-online-learning-educational-productivit $\mathrm{y}$

Barker, P. (2002). On being an online tutor. Innovations in Education and Teaching International, 39(1), 7-13. https://doi.org/10.1080/13558000110097082

Bennett, S., \& Marsh, D. (2002). Are we expecting online tutors to run before they can walk? Innovations in Education and Teaching International, 39(1), 14-20. https://doi.org/10.1080/13558000110097055

Berge, Z. (2013). E-Moderating: the key to teaching and learning online. Journal of Distance Education, 34(3), 391-395. https://doi.org/10.1080/01587919.2013.835769

Betts, K. (2017). The growth of online learning: How universities must adjust to the new norm. Retrieved on September 24, 2018, from https://www.educationdive.com/news/the-growth-of-online-learning-how-universities-must-adjust-to-the-ne w-norm/433632/

Bett, K., \& Birgit, G. (2004). E-Moderation (in German).

Blake, R. (2011). Current trends in online language learning. Annual Review of Applied Linguistics, 31, 19-35. https://doi.org/10.1017/S026719051100002X

Brychan, T., Paul, J., Gary, P., \& Christopher, M. (2004). Student Perceptions of Effective E-moderation: A Qualitative Investigation of E-College Wales.

Chang, H., \& Windeatt, S. (2016). Developing collaborative learning practices in an online language course. $\begin{array}{llll}\text { Computer-Assisted Language } \quad \text { Learning, 29(8), } & \text { 1271-1286. }\end{array}$ https://doi.org/10.1080/09588221.2016.1274331

Chowcat, I. (2005). Models of e-learning: the importance of context. Paper presented at ALT-C 12th International Conference Manchester University UK.

Coghlan, M. (2001). E-MODERATION - Managing a New Language? Paper presented at the Net*Working 2001 Conference - from Virtual to Reality, Brisbane, October 2001.

Conole, G., de Laat, M., Dillon, T., \& Darby, J. (2006). Student experiences of technologies. JISC LXP Final report. Retrieved August 03, 2007, from http://www.jisc.ac.uk/media/documents/programmes/elearning_pedagogy/lxp\%20project\%20final\%20repor t \%20dec\%2006.pdf\# Creanor

Crowley, J., \& Ryan, M. (2017). The five key challenges in implementing ICT for development. Retrieved September $\quad 1$, 2017, from https://www.devex.com/news/the-five-key-challenges-in-implementing-ict-for-development82499

Davis, F. D. (1989). Perceived usefulness, perceived ease of use, and user acceptance of information technology. MIS Quarterly, September, 319-340. https://doi.org/10.2307/249008

Friedman, J. (2018). 4 Expectations for Online Education in 2018. Retrieved September 24, 2018, from https://www.usnews.com/higher-education/online-education/articles/2018-01-18/4-expectations-for-onlineeducation-in-2018

Good, M. (2001). On the way to online pedagogy Teaching and learning online: pedagogies for new technologies (pp. 166, 174). Stephenson J. Kogan Page London.

Gray, D. E., Ryan, M., \& Coulan, A. (2003). The training of Teachers and Trainers: Innovative Practices, Skills and Competencies in the use of e-learning. Open Distance e-learning.

Hughes, M., Ventura, S., \& Dando, M. (2004). On-line interprofessional learning: introducing constructivism through enquiry-based learning and peer review. Journal of Interprofessional Care, 18(3), 263-268. https://doi.org/10.1080/13561820410001731304

Jaffer, S., Ng'ambi, D., \& Czerniewicz, L. (2011). The role of ICTs in higher education in South Africa: One strategy for addressing teaching and learning. 
Jones, N., \& Peachey, P. (2005). The development of socialization in an on-line learning environment. Journal of Interactive Online Learning, 3(3), 1-20.

Khan, B. H. (2004). Comprehensive approach to program evaluation in open and distributed learning (CAPEODL) model. Introduced in the Program Evaluation course. George Washington University

Lee, E., \& Oh, S. (2018). Computer-Mediated Communication. Retrieved April 21, 2018, from www.oxfordbibliographies.comlviewldocument/obo-9780199756841lobo-9780199756841-0160.xmi\#back ToTop

Levy, M. (1997). CALL: Context and conceptualization. Oxford: oxford university press.

Li, M. (2018). Computer-mediated collaborative writing in L2 contexts: an analysis of empirical research. Computer-Assisted Language Learning, 31(8), 882-904. https://doi.org/10.1080/09588221.2018.1465981

Light, D. (2009). The role of ICT in enhancing Education in Developing Countries: Findings from an Evaluation of the Intel Teach Essentials course in India, Turkey, and Chile. Journal of Education for International Development, $4,2$.

Lisewski, B., \& Joyce, P. (2003). Examining the five-stage e-moderating model: designed and emergent practice in the learning technology profession. Research in Learning Technology, 11(1) 55-66. https://doi.org/10.3402/rlt.v11i1.11267

Manchester University. (2018). Blackboard Training Resources. Retrieved September 28, 2018, from media.humanities.manchester.ac.uk/humanities/_repository/bb_docs/User_documentation/bb_staffdev_intro pedagogy_v1_3final.pdf

Menchaca, M., \& Khawaldeh, N. (2014). Barriers to utilizing ICT in education in Jordan. Retrieved September 29, 2018, from https://www.researchgate.net/publication/266387215_Barriers_to_utilizing_ICT_in_education_in_Jordan

MGH Institute. (2018). Benefits and challenges of online instruction. NW.INSTITUTE.edu

Moule, P. (2002). Evaluation of a basic life support CD-ROM: its effectiveness and user experiences. Educational Technology and Society, 5(3), 163-174.

Moule, P. (2005). E-learning for healthcare students: developing the communities of practice framework. University of the West of England Bristol 2005 Ed.D. thesis.

Moule, P. (2006). E-learning for healthcare students: developing the Communities of Practice framework. Journal of Advanced Nursing, 53(3), 370-380. https://doi.org/10.1111/j.1365-2648.2006.03813.x

Moule, P. (2006a). E-communities E-learning in nursing. In S. Glen \& P. Moule (Eds.), Palgrave Basingstoke. https://doi.org/10.1007/978-1-137-08846-8_3

Moule, P. (2007). Challenging the five-stage model for e-learning: a new approach. ALTJ Research in Learning Technology, 15(1), 37-50. https://doi.org/10.3402/rlt.v15i1.10911

Moule, P., \& Gilchrist, M. (2001). An evaluation of a basic life support CD-ROM. Health Informatics Journal, 7(1), 28-35. https://doi.org/10.1177/146045820100700106

Ni, A. (2018). Comparing the Effectiveness of Classroom and Online Learning: Teaching Research Methods. Retrieved September 28, 2018, from www.naspaa.org/jpaemessenger/Article/VOL19-2/03_Ni.pdf

Oliver, R. (2011). Exploring benchmarks and standards for assuring quality online teaching and learning in higher education. Proceedings of 16th open and distance learning association of Australia Biannual forum, Canberra, October.

Piccoli, R., \& Ahmad, I. B. (2001). Web-based virtual learning environments: A research framework and a preliminary assessment of effectiveness in basic IT skills training. MIS Quarterly, 25(4), 401-426. https://doi.org/10.2307/3250989

Rogers, J. (1995). The diffusion of innovations. New York, Free Press.

Rogers J. (2000). Communities of practice: a framework for fostering coherence in virtual learning communities. Educational Technology and Society, 3(3), 1-12. Retrieved March 11, 2003, from http://ifets.ieee.org/periodical/vol_3_2000/eo1.html

Rusby, N. J. (1979). An introduction to educational computing. London: Croom Helm.

Salmon, G. (2000). E-moderating: the key to teaching and learning online. London, Kogan Page. 
Salmon, G. (2002). E-activities. London, Kogan Page.

Salmon, G. (2003). E-moderating (2nd ed.). London, Routledge Falmer.

Salmon, G. (2004). E-moderating: The Key to Teaching and Learning Online. London: Taylor \& Francis. https://doi.org/10.4324/9780203465424

Salmon, G. (2016). Flying not flapping: a strategic framework for e-learning and pedagogical innovation in higher education institutions. Journal ALT-J, 13(3), 201-218. https://doi.org/10.3402/rlt.v13i3.11218

Salmon, G. (2018). Salmon's five-stage model. Retrieved October 2, 2018, from https://www.gillysalmon.com/five-stage-model.html.47-

Schmidt, K., \& Brown, D. (2004). A Model to Integrate Online Teaching and Learning Tools into the Classroom. Journal of Technology Studies, 30(2), 86-92. https://doi.org/10.21061/jots.v30i2.a.4

Sharifi, M., AbuSaeedi, A., Jafaygohar, M., \& Zandi, B. (2018). Retrospect and prospect of computer assisted English language learning: a meta-analysis of the empirical literature. Computer-Assisted Language Learning, 31(4), 413-436. https://doi.org/10.1080/09588221.2017.1412325

Shulze, M., \& Scholz, K. (2017). Learning trajectories and the role of online courses in a language program. Computer-Assisted Language Learning, 31(3), 185-205. https://doi.org/10.1080/09588221.2017.1360362

Somekh, B., \& Pearson, M. (2000). Inter-cultural learning arising from pan-European collaboration using electronic communications: sub-text or substance? Paper presented at the British Educational Research Association Annual Conference Cardiff UK September 2000.

Sun, R. J., Tsai, G., Finger, Y.-Y., \& Chen, D. Y. (2008). What drives a successful eLearning? An empirical investigation of the critical factors influencing learner satisfaction. Computers \& Education, 50(4), 11831202. https://doi.org/10.1016/j.compedu.2006.11.007

Sydorenko, T., Daurio, P., \& Thorne, S. (2017). Refining pragmatically-appropriate oral communication via computer-simulated conversations. Computer-Assisted Language Learning, 31(1/2), 157-180. https://doi.org/10.1080/09588221.2017.1394326

Thorpe, M. (2002). Rethinking learner support: the challenge of collaborative online learning. Open Learning, 17(2), 105-115. https://doi.org/10.1080/02680510220146887a

Vygotsky, L. (1978). Mind in society. Harvard University Press.

Watts, N. (2010). Reflecting on Models for Online Learning in Theory \& Practice. AISHE-J: The All Ireland Journal of Teaching and learning in Higher Education, 2(1), 1-19.

Wenger, E. (1998). Communities of practice. Cambridge University Press Cambridge.

Yusuf, M. O. (2011). Information and communication education: Analyzing the Nigerian national policy for information technology. International Education Journal, 6(3), 316-321.

Zhang, D., \& Wang, X. (2017). The effects of the CALL model on college English reading teaching. International Journal of Emerging Technologies in Learning, 12(12), 24-35. https://doi.org/10.3991/ijet.v12i12.7954

\section{Copyrights}

Copyright for this article is retained by the author, with first publication rights granted to the journal.

This is an open-access article distributed under the terms and conditions of the Creative Commons Attribution license (http://creativecommons.org/licenses/by/4.0/). 